\title{
Kongresse - vom Charme des Kleinen
}

\section{Dominik Heim}

PD Dr. med., ehemaliger Chefarzt Chirurgie, Spital Frutigen, Ehrenmitglied der Schweizerischen Gesellschaft für Chirurgie und Ehrenmitglied der European Society for Trauma and Emergency Surgery, Mitglied FMH

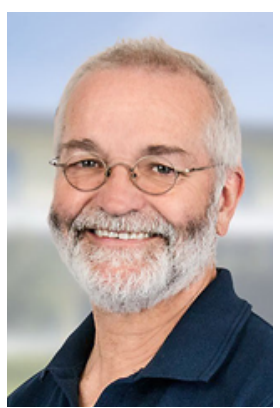

Es ist eindeutig - klein hat Mühe! Die Mail ging an hunderteinundzwanzig Mitglieder: Füllen wir das Hotel nicht, gibt es keinen Kongress. Das wäre jammerschade. Denn er findet in Roscoff am Ärmelkanal statt. Dort, wo es immer windet, wo die Artischocken wachsen und wo Commissaire Dupin seine eigenartigen Fälle zu lösen hat [1]. Lösen könnte er sie als Pariser im Exil in der Provinz gar nicht, wäre da nicht Nolweyn, seine einheimische Sekretärin, die ihm mit ihrer Einsicht in die bretonischen Verhältnisse und Fabeln jene Hilfe bieten kann, die schlussendlich nach vielen Seiten Belletristik doch noch die Antwort bringt. Da bietet sich jetzt eine Nebenbemerkung an: Wer in seinem (Medizinal-)Beruf nicht von da ist, der braucht jemanden, der es ist. Den sozio-psycho-ökonomischen Hintergrund erfahren wir auch bei bester Anamnese nicht immer auf Anhieb, die einheimische MPA aber kennt ihn!

Aber es muss nicht immer Dupin sein, dies in leiser Anspielung auf das Kultbuch vom Kaviar von Johannes Mario Simmel aus den 60er Jahren [2] - ja, ich weiss, immer diese Bezüge auf die Kultur von früher, die die jungen Leser ja gar nicht kennen können! Aber man darf doch ein paar kleine Amuse-Bouches platzieren, oder? Und es ist sicher nicht falsch, auch etwas über die Vergangenheit im Sinne eines guten Allgemeinwissens zu wissen.

Die Geschichte vom Kongress am Ärmelkanal ist kein Einzelbeispiel. Da war der SITEMSH-Kongress [3], den die Teilnehmer wegen seiner hochstehenden Wissenschaftlichkeit rühmten. Nur, diese Perlen hörten eigentlich wenige Kongressteilnehmer. Wäre da nicht das selbstlose Engagement der nationalen Sekretäre, die aus Tradition sogar auch als Referenten ihre Kongressbeiträge bezahlen, es wäre ein finanzielles Debakel geworden. Aber dank diesem Goodwill existiert diese Gesellschaft auch heute noch. Und sie ist wahrscheinlich die wichtigste, kompetenteste medizinische Gesellschaft für Wintersportverletzungen.

Auch im eigenen Lande gibt es kleinere Gesellschaften, die mit ihrer Thematik eigentlich viele Leute ansprechen müssten und doch um ihre Existenz kämpfen: Traditionell sind die Bieler Fortbildungstage (www. sgact.ch) gewachsen, ihre Mission ist die Allgemein- chirurgie, die mindestens in der ländlichen Umgebung nach wie vor einen hohen Stellenwert verdient (für die Agglomeration ist das spezialisierte Zentrumsspital die «Bezugsperson" geworden). Die Teilnehmerzahl schrumpft, für die Industrie ist dieser Schrumpfungsprozess ein Anlass wegzubleiben, und mit roten Zahlen verliert eine Mission ihre Existenzgrundlage. Dagobert Duck regiert längst auch in der Medizin. Die Fallzahlen sind die Maxime der Wirtschaftlichkeit, die fachliche Qualität riskiert dabei zur Luftblase zu werden - wussten Sie schon, dass rund 40 Prozent der zur Beurteilung vorgelegten Dossiers mit der Frage nach einem Behandlungsfehler heute bejaht werden müssen?! Kleine Kongresse leben vom Engagement der Promotoren und von einer verständigen Industrie, sie erlauben einen persönlichen Kontakt unter den Teilnehmern, auch mit der Faculty, Sozialisierung nennt man das, glaub ich, heute. Aktive Teilnahme wird grossgeschrieben, ein Untergehen in der Masse ist fast unmöglich. Und es ist weniger steril, als sich PDFs von Kongressvorträgen vom Netz «reinzuziehen». Ich behaupte, dass der Lerneffekt weitaus höher ist als im E-Learning und an den Mammutkongressen mit Tausenden von Teilnehmern. Wer nicht scheu ist, der besucht kleine Kongresse, lernt auf Augenhöhe die Teilnehmer und die Faculty kennen, lässt sich Probleme und ihre Lösungsansätze persönlich erklären.

Wir sehen uns an den Bieler Fortbildungstagen vom 6.-7. September 2018. Dort wird übrigens auch Kultur geboten, aber das ist medizinisch dann doch schon fast wieder unüblich!

PS: Dieses Inserat, das in der SonntagsZeitung erschienen ist, will ich dem geneigten Leser nicht vorenthalten: «Das beste Brot gibt's beim Bäcker. Also bei uns.» Es stammt von der Migros! Besser kann man den Globalisierungsprozess nicht darstellen! Und es passt so gut zum obigen Thema ...

\section{Bildnachweis \\ (C) Hohmad}

\section{Literatur}

1 Bannalec JL. Bretonische Verhältnisse. Goldmann; 2013.

2 Simmel JM. Es muss nicht immer Kaviar sein. Knaur; 1960.

3 Heim D. Prevention is better than healing. Schweiz Ärztezeitung. 2018;99(6):188-90 